\title{
Comparison of chemiluminescent microparticle immunoassay with electrochemiluminescence immunoassay for carcinoembryonic antigen
}

\author{
Nafija Serdarevic ${ }^{1,2 *}$, Jasmina Smajic ${ }^{1}$ \\ 'Institute for Clinical Biochemistry and Immunology , University Clinical Center Sarajevo, Sarajevo, Bosnia and Herzegovina, \\ ${ }^{2}$ Faculty of Health Sciences, Bolnicka 25, Sarajevo, Bosnia and Herzegovina
}

\begin{abstract}
Introduction: Carcinoembryonic antigen (CEA) is used for monitoring of disease progression and treatment response in cancer patients. The aim was to compare the performance of chemiluminescent microparticle immunoassay with electrochemiluminescence immunoassay for CEA.

Methods: A total of 115 samples were collected during routine diagnostic, prognostic, and therapy monitoring procedures in patients with colorectal and pancreatic cancer. We used Architect i2000SR and Cobas E601 for CEA analysis in sera samples.
\end{abstract}

Results: The correlation coefficient of 0.984 (95\% confidence interval [Cl]: 0.972-0.991) for results obtained on both platforms was observed for CEA $\leq 10 \mathrm{ng} / \mathrm{mL}$ group. Moreover, intercept of 0.9027 (95\% $\mathrm{Cl}$ : 0.705-1.099) and slope 0.8076 (95\% Cl: 0.765-0.8498) $(p<0.0001)$ were observed in this group. In CEA $>10 \mathrm{ng} / \mathrm{mL}$ group, we observed slope $=1.1986(95 \% \mathrm{Cl}: 1.1474-1.2498)(p<0.0001)$, intercept $=-11.69(-17.53--5.84)$, and correlation coefficient $=0.985$ (95\% Cl: 0.976-0.9914). Mean differences between assays in group $\leq 10 \mathrm{ng} / \mathrm{mL}$ and $>10 \mathrm{ng} / \mathrm{mL}$ were 0.2066 (95\% Cl: 0.0019-0.4113) and -2.66 (95\% Cl: $-10.10-4.76) \mathrm{ng} / \mathrm{mL}$, respectively.

Conclusion: Although there were differences, based on 20 days' precision tests, overall results showed a good analytical performance and correlation between CEA assays on Architect i2000SR and Cobas E601 platforms. Reference intervals appropriate for the method of CEA measurement should be used. The standardization and harmonization of serum CEA concentration assays are needed.

Key words: Carcinoembryonic antigen; chemiluminescent microparticle immunoassay; electrochemiluminescence immunoassay; immunoassays

\begin{abstract}
*Corresponding author: Nafija Serdarevic, Institute for Clinical Chemistry and Biochemistry, University Clinical Center Sarajevo, Bolnicka 25, 71000 Sarajevo, Bosnia and Herzegovina.

E-mail: serdarevicnafija@yahoo.com
\end{abstract}

Submitted: 28 May 2018/Accepted: 30 July 2018

DOI: https://doi.org/10.17532/jhsci.2018.520

UNIVERSITY OF SARAJEVO FACULTY OF HEALTH STUDIES

\section{INTRODUCTION}

Cancer can be detected and monitored using biologic tumor markers. Tumor markers are produced either directly by the tumor or as an effect of the tumor on healthy tissue. Ideally, a tumor marker would be tumor specific, absent in healthy individuals, and 
readily detectable in body fluids. Unfortunately, all of the currently available tumor markers do not fit this ideal model (1). Carcinoembryonic antigen (CEA) is a large glycoprotein with molecular weight of approximately $200 \mathrm{kD}$. CEA is the most widely used tumor marker for colorectal cancer and is also frequently elevated in a lung, breast, and gastrointestinal tumors (2). Most studies have adopted a CEA cutoff point $<3.0 \mathrm{ng} / \mathrm{mL}$ for healthy non-smokers, between 3.0 and $5.0 \mathrm{ng} / \mathrm{mL}$ for healthy smokers, gray zone for levels between 5.0 and $10.0 \mathrm{ng} / \mathrm{mL}$, cancer for levels between 10.0 and $20.0 \mathrm{ng} / \mathrm{mL}$, and metastasis for levels $>20.0 \mathrm{ng} / \mathrm{mL}(3,4)$. In colon cancer, CEA is used for prognosis, postsurgery surveillance, and chemotherapy response monitoring (5). CEA determination is available on numerous automated analysis platforms. Due to the high heterogeneity of polyclonal antibodies for CEA, it is advised that the same assay is used for serial monitoring (6). In competitive chemiluminescence assay, patient antigen and labeled antigen compete for the limited number of antibody binding sites. Free and bound reagent antigen must be separated before the label is measured. The label may be measured on either free or bound reagent antigen and is related to the amount of patient antigen in the sample. The chemiluminescence is produced by compounds such as luminol and acridinium esters that can produce light energy by chemical reaction. On separation of free and bound reagent antigen, an enzyme (usually firefly luciferase) is used to produce chemiluminescence, which is measured with a luminometer (7). Harmonization of results among different clinical laboratory measurement procedures may be achieved by calibration traceability (8). The International Organization for Standardization standard 17511: 2003 published a material which provides the framework for calibration traceability in laboratory medicine (9). Automated immunoassays may have different methodology principle, antigens, epitopes, and reagents. Thus, CEA concentration obtained by different automated analyzers is different, and harmonization of CEA concentration results obtained using different immunoassays has not yet been achieved (10).

The aim was to compare the performance of chemiluminescent microparticle immunoassay (CMIA) with electrochemiluminescence immunoassay (ECLIA) for CEA.

\section{METHODS}

\section{Test procedure}

In our study, assays were performed according to the manufacturers' instructions. The CMIA is a non-competitive sandwich assay technology used to measure analytes. The amount of signal is directly proportional to the amount of analyte present in the sample. Architect (Abbott) CEA assay is a two-step immunoassay to determine the presence of CEA in human serum using CMIA technology. The reference range for CEA in Architect CMIA is $0-3 \mathrm{ng} / \mathrm{mL}$. ARCHITECT (CMIA) detection limit is $0.5 \mathrm{ng} / \mathrm{mL}$ at the $95 \%$ level of confidence and measuring range $0.5-1500 \mathrm{ng} / \mathrm{mL}$. The ECLIA is based on the use of a ruthenium complex and tripropylamine. The Cobas E601 (Roche, Basel, Switzerland) detection limit is $0.2 \mathrm{ng} / \mathrm{mL}$ and measuring range is $0.20-1000 \mathrm{ng} / \mathrm{mL}$. The reference range of CEA in Cobas E601 ECLIA technology for healthy non-smokers is $0-3.8 \mathrm{ng} / \mathrm{mL}$ and for healthy smokers is $0-5.0 \mathrm{ng} / \mathrm{mL}$ (9). We performed measurements of CEA with single reagent lot and single calibrator lot; CEA calibrator lot; Architect i2000SR (Abbott, cat. no. 61019FN00), and Cobas E601 (Roche Diagnostics; CEA cat. no. 2699370). The Abbott (Architect i2000SR) calibrator contains internal standard manufactured using highly purified material and Roche (Cobas E601) calibrator contains $1^{\text {st }}$ International Reference Pricing World Health Organization reference standard 73/601.

\section{Patients}

This study was conducted from July 2017 to April 2018 and included 115 patients (70 male and 45 female), between 65 and 85 years old, hospitalized at the Oncology Clinic, University Clinical Center Sarajevo. The patients' samples were collected in serum separator Vacutainer test tubes (Becton Dickinson, Rutherford, NJ, U.S.) in a volume of $3.5 \mathrm{~mL}$. Serum samples were obtained by centrifugation at $3000 \mathrm{rpm}$ using Centrifuge SIGMA 3-16P (SIGMA Laborzentrifugen GmbH, Osterode am Harz, Germany). After centrifuging, serum concentration of CEA was determined. The study protocol followed the ethical guidelines given in the Declaration of Helsinki, 
and informed consent was obtained from all participants. Patients' samples were collected and assigned to four groups according to the Architect CEA values: CEA $<2.5 \mathrm{ng} / \mathrm{mL}$ (10 samples), $2.5-5.0 \mathrm{ng} / \mathrm{mL}$ (20 samples), $5.0-10 \mathrm{ng} / \mathrm{mL}$ (20 samples), and $\geq 10.0 \mathrm{ng} / \mathrm{mL}$ (65 samples).

\section{Patients' inclusion and exclusion criteria}

In our study, serum concentration of CEA was determined as a part of the diagnosis, prognosis, and therapy monitoring of colorectal and pancreatic cancer. The patients with renal failure and fulminant hepatitis have falsely increased CEA values. Furthermore, patients with hypothyroidism may also have elevated levels of CEA. The levels of CEA may be raised in some non-neoplastic conditions such as ulcerative colitis, pancreatitis, cirrhosis, chronic obstructive pulmonary disease, and Crohn's disease. Therefore, patients with the conditions mentioned above were excluded from the study. Since hemolysis, icterus, and lipemia can affect tumor marker immunoassay measurements, such samples were excluded from the study as well (11).

\section{Serum samples}

Serum samples were collected, separated from the clot, and stored at $2-8^{\circ} \mathrm{C}$ for up to $24 \mathrm{~h}$. If measurements were not performed within $24 \mathrm{~h}$, the samples were stored at $-20^{\circ} \mathrm{C}$. To prevent thawing effects, each sample was aliquoted in two aliquots, i.e., one aliquot per assay. Aliquots were stored in the same manner as mentioned, to avoid variation in storage conditions (12).

\section{Imprecision}

Quality control was performed using corresponding commercial control samples with low, medium, and high CEA concentrations for Architect i2000SR and Cobas E601 provided by the manufacturers. We analyzed precision (intra-assay variation) by measuring CEA using control samples for ARCHITECT i2000SR and Cobas E601 $(n=20)$. The reproducibility (interassay variation) was tested with the same control samples once a day over 10 consecutive days. Recovery studies were performed in both the systems (Architect and Cobas) for CEA.

\section{Statistical analysis}

Statistical analysis was performed using MedCalc software and SPSS version 16.0 software (SPSS Inc., Chicago, USA). Data were analyzed using descriptive statistic average values $(\mathrm{x})$, standard deviation (SDs), Pearson correlation coefficient $(r)$, and equations of linear regression. The method of comparison was Passing and Bablok. The analysis was performed using Bland-Altman plot to test the limits of agreement. The difference between the samples was analyzed using paired $t$-test, with the statistical significance level set at $p<0.001$.

\section{RESULTS}

\section{Quality control testing}

Three types of controls $(n=20)$ with low, medium, and high levels of CEA were used for quality control testing. The results of quality control testing for the two immunoassays are shown in Table 1.

\section{Accuracy testing}

We compared CEA concentrations measured in 115 by Architect i2000SR (CMIA) and Cobas E601 (ECLIA) technology. CEA assays differ by a constant factor as shown by the intercept $=0.9027(95 \%$ confidence interval [CI]: 0.705-1.099). The proportional difference was observed, shown by the slope $=0.8076(95 \%$ CI: $0.765-0.8498)$ $(p<0.0001)$. The Cusum test of linearity was $p=0.26$. The regression equation for CEA $\leq 10 \mathrm{ng} / \mathrm{mL}$ group was $\mathrm{y}=0.9027+0.81776 \mathrm{x}$. The correlation coefficient of 0.984 (95\% CI: 0.972 0.991) was observed for the same group (Figure 1). In the CEA $>10 \mathrm{ng} / \mathrm{mL}$ group, we obtained following results following regression analysis statistics: Slope $=1.1986$ (95\% CI: $1.1474-1.2498)$ $(p<0.0001)$; intercept $=-11.69$ (95\% CI: -17.53 $-5.84)$; and correlation coefficient $=0.985(95 \%$ CI: 0.976-0.9914). Furthermore, regression equation within this group was $\mathrm{y}=3.617807+1.04390 \mathrm{x}$ in Figure 2. The average mean values for CEA $(\leq 10 \mathrm{ng} / \mathrm{mL}$ ) group measured by Abbott and Roche assay were $3.11 \mathrm{ng} / \mathrm{mL}$ and $3.82 \mathrm{ng} / \mathrm{mL}$, respectively (95\% CI: $2.76-4.46 \mathrm{ng} / \mathrm{mL}$ and $3.12-4.52 \mathrm{ng} / \mathrm{mL}$, respectively). Method comparison analysis using Bland-Altman plot to test limits of agreement $(-1.96 s-+1.96)$ between Abbott and Roche assay 
TABLE 1. Quality control testing

\begin{tabular}{ccccc}
\hline $\begin{array}{l}\text { Concentration } \\
\text { spiked }(\mathrm{ng} / \mathrm{mL})\end{array}$ & $\begin{array}{c}\text { Concentration found intraassay } \\
(\mathrm{Mean} \pm \mathrm{SD}, n=20)(\mathrm{ng} / \mathrm{mL})\end{array}$ & $\begin{array}{c}\text { Precision } \\
\text { intraassay }(\%)\end{array}$ & $\begin{array}{c}\text { Concentration found interassay } \\
(\text { Mean } \pm S D, n=20)(\mathrm{ng} / \mathrm{mL})\end{array}$ & Reproducibility $(\%)$ \\
\hline Architect CEA assay CMIA technology & & & \\
$3.30-6.70$ & $4.8 \pm 0.16$ & 3.5 & $4.5 \pm 0.16$ & 3.7 \\
$13.0-27.0$ & $19.9 \pm 0.55$ & 2.8 & $20.1 \pm 0.60$ & 3.0 \\
$65.0-135.0$ & $99.12 \pm 2.08$ & 2.1 & $97.3 \pm 2.62$ & 2.7 \\
Cobas CEA assay ECLIA technology & & & \\
$3.36-6.40$ & $3.79 \pm 0.09$ & 2.5 & $3.92 \pm 0.14$ & 3.70 \\
$35.6-54.5$ & $37.58 \pm 0.63$ & 1.7 & $39.4 \pm 1.22$ & 3.10 \\
\hline
\end{tabular}

SD: Standard deviation, CEA: Carcinoembryonic antigen, CMIA: Chemiluminescent microparticle immunoassay,

ECLIA: Electrochemiluminescence immunoassay

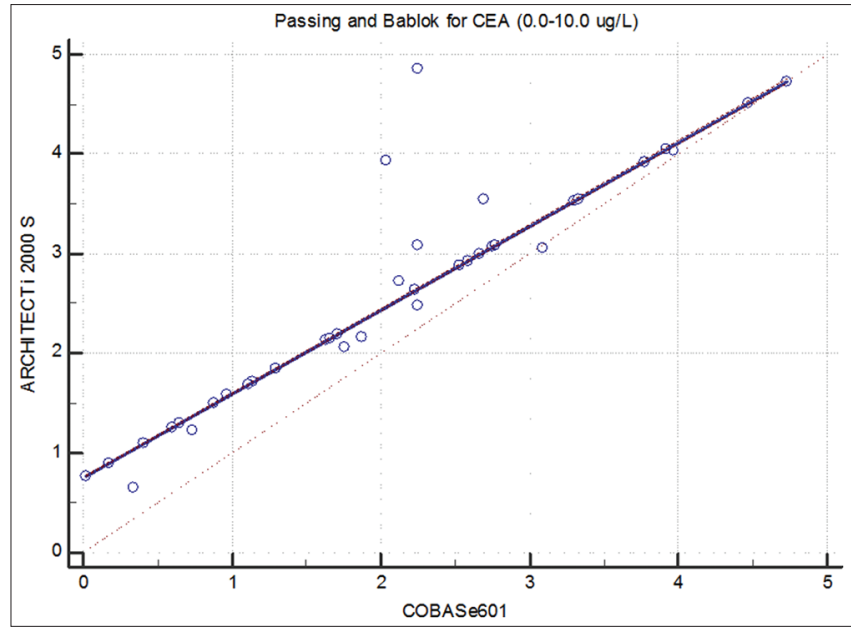

FIGURE 1. Comparison of carcinoembryonic antigen (CEA) concentration in CEA $\leq 10 \mathrm{ng} / \mathrm{mL}$ group using Architect i2000SR immunoassay analyzer and Cobas E601 analyzer $(r=0.972-0.991)$.

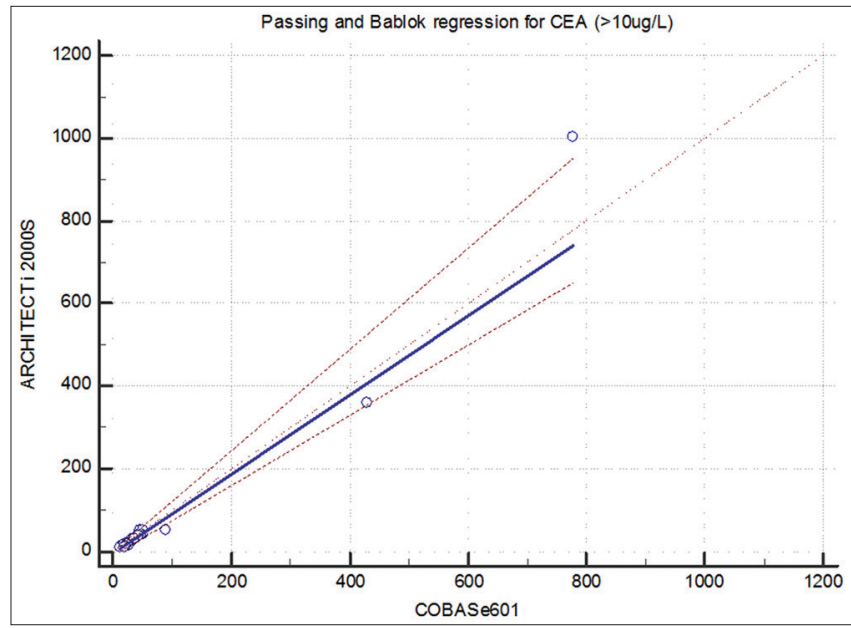

FIGURE 2. Comparison of carcinoembryonic antigen (CEA) concentration in CEA $>10 \mathrm{ng} / \mathrm{mL}$ group using Architect i2000SR immunoassay analyzer and Cobas E601 analyzer $(r=0.976-0.9914)$. 
for CEA $\leq 10 \mathrm{ng} / \mathrm{mL}$ - group showed mean difference of 0.2066 (95\% CI: $0.0019-0.4113) \mathrm{ng} / \mathrm{mL}$ (Figure 3). In CEA $\geq 10 \mathrm{ng} / \mathrm{mL}$ group, mean difference was -2.66 (95\% CI: $-10.10-4.76) \mathrm{ng} / \mathrm{mL}$ (Figure 4). The results of our study have shown that average mean values of CEA in CEA $\geq 10 \mathrm{ng} / \mathrm{mL}$ group measured by Abbott and Roche assay were $42.76 \mathrm{ng} / \mathrm{mL}$ and $45.43 \mathrm{ng} / \mathrm{mL}$, respectively $(95 \%$ CI: $10.95-71.59 \mathrm{ng} / \mathrm{mL}$ and $19.26-74.56 \mathrm{ng} / \mathrm{mL}$, respectively). The concordance between the results was high in lower and higher CEA concentrations.

\section{DISCUSSION}

In our study, we compared two widely used automated CEA assays. $80 \%$ of healthy subjects have CEA concentration $<3 \mathrm{ng} / \mathrm{mL}$ (13). In Architect CMIA and Cobas ECLIA based on the LeveyJennings quality control test report, was $<2 \mathrm{SD}$. The results of Levey-Jennings report confirm very good quality control. In our study, CMIA technology has precision $2.1-3.5 \%$ and reproducibility $2.7-3.7 \%$. The other method technology ECLIA had the precision of $1.7-2.5 \%$ and reproducibility of $3.1-3.7 \%$ (Table 1). The investigation of Hendriks et al. (14)

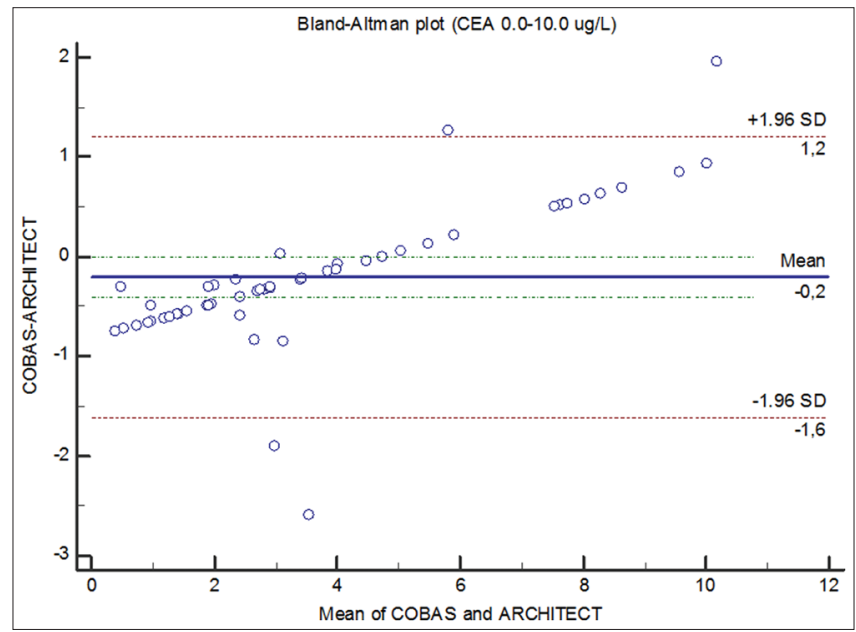

FIGURE 3. Comparison of two methods Cobas E601 and Architect i2000SR for carcinoembryonic antigen (CEA) $\leq 10 \mathrm{ng} / \mathrm{mL}$ group. The bias mean difference was 0.2066 (95\% confidence interval: 0.0019-0.4113) ng/mL.

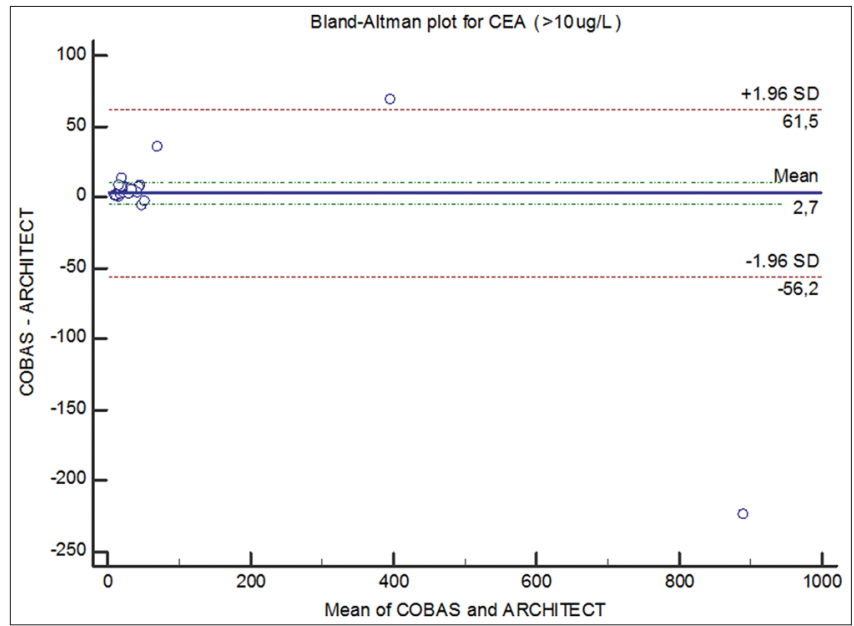

FIGURE 4. Comparison of two methods Cobas E601 and Architect i2000SR for CEA >10 ng/mL group. The bias mean difference is -2.66 (95\% confidence interval: $-10.10-4.76) \mathrm{ng} / \mathrm{mL}$. 
has shown that CMIA technology had the precision of $2.5-3.5 \%$ and ECLIA had the precision of 2.5$5.1 \%$. In our study, we obtained a high concordance of results in CEA $\leq 0-10 \mathrm{ng} / \mathrm{mL}$ group between Architect and Cobas. We have shown regression analysis slope $=0.8076$ (95\% CI: $0.765-0.8498)$ and intercept $=0.9027$ (95\% CI: 0.705-1.099) with high correlation coefficient $r=0.972-0.991$ and $p<$ 0.0001 as shown in Figure 1. The method comparison of the assays for the CEA $>10 \mathrm{ng} / \mathrm{mL}$ resulted in the following regression analysis statistic: Slope $=1.1986$ (95\% CI: 1.1474-1.2498) ( $p<0.0001)$, intercept $=-11.69(95 \% \mathrm{CI}:-17.53--5.84)$, and the correlation coefficient $=0.985$ (95\% CI: 0.976 $0.9914)$, and $p<0.0001$ was observed in this group, as shown in Figure 2. Previous studies have shown a good correlation between Architect (Abbott) and Elecsys E170 (Roche) $(r=0.994)(12)$. The Cusum test for linearity for the CEA $\leq 10 \mathrm{ng} / \mathrm{mL}$ group obtained $p=0.74$ and for the CEA $>10 \mathrm{ng} /$ $\mathrm{mL}$ group obtained $p=0.15$. The study of the comparison of CEA immunoassays Architect i2000SR (Abbott) and Elecsys E170 (Roche) has shown Cusum test for linearity $p$-value of 0.33 for CEA $<100 \mathrm{ng} / \mathrm{mL}$ (15). The results of our study showed that three patients had CEA serum values $>5 \mathrm{ng} /$ $\mathrm{mL}$ measured by the Cobas E601, while the values were within reference range measured by Architect i2000SR. Four of patients had CEA serum values $>10 \mathrm{ng} / \mathrm{mL}$ measured by Cobas E601 while values were $<10.0 \mathrm{ng} / \mathrm{mL}$ in a gray zone when measured by Architect i2000SR. The CEA cut-off point is below $3.0 \mathrm{ng} / \mathrm{mL}$, grey zone between 5.0 and $10.0 \mathrm{ng} /$ $\mathrm{mL}$ and cancer between 10.0 and $20.0 \mathrm{ng} / \mathrm{mL} .(3,4)$ The Cobas ECLIA limit of detection for CEA was $0.2 \mathrm{ng} / \mathrm{mL}$ and for Architect CMIA was $0.5 \mathrm{ng} /$ $\mathrm{mL}$. The difference in the limit of detection could be one of the explanations of result differences in CEA determination using ECLIA and CMIA technology. We have shown that even though CEA values in Architect i2000SR and Cobas E601 assays highly correlate in all CEA concentration intervals $<10 \mathrm{ng} / \mathrm{mL}$ and $\geq 10 \mathrm{ng} / \mathrm{mL}$, they are not the same. The Architect i2000SR assay overall provided results 5.8-6.2\% lower than the Cobas E601 results.

Furthermore, at a critical concentration of $10 \mathrm{ng} / \mathrm{mL}$, a $6.2 \%$ relative difference was observed, with higher values being observed in Cobas E601.
The differences between assay measurements are of sufficient magnitude that CEA results are not interchangeable. The detection method for the architect i2000SR is chemiluminescence and for Cobas E601 is electrochemiluminescence. There is no reason to assume that one is more accurate than the other; however, users of the assays must be aware of these differences. The investigation from Park et al. (15) has shown the mean difference between the CMIA and ECLIA technologies from $1.2 \%$ to 2.2\% where Architect had lower results than the Cobas E601. The Architect had a lower concentration of CEA in comparison with the previous method of Roche (Elecsys E170 and Elecsys 2010). The differences might be explained due to the diluent matrix effects or interactions between components from blood collection tubes and blood samples $(14,15)$. It is empirically known that repetitive sampling using different methods may show significant variations in results; this fact, if not taken into account, this could lead to inappropriate clinical decisions (16-20). The results of our study showed that the mean difference in CEA concentration in group $\leq 10 \mathrm{ng} / \mathrm{mL}$ was 0.2066 (95\% CI: 0.0019 0.4113), as shown in Figure 3. Mean differences of CEA concentration in CEA $>10 \mathrm{ng} / \mathrm{mL}$ group was -2.66 (95\% CI: $-10.10-4.76) \mathrm{ng} / \mathrm{mL}$, as shown in Figure 4. Similar comparison method results were reported in a study by Sturgeon et al. (12). The differences in reference range for each immunoassay and instrument-specific calibration and working standard could result in inconsistent CEA results between assays. Precautions should be taken since CEA concentration from automated immunoassays is not comparable $(10,15)$. The main limitation of our study is a small number of samples and the non-Gaussian distribution of CEA concentration present in the whole study population.

\section{CONCLUSION}

The results of our study showed a good analytical performance and correlation of CEA assays based on 20 days of precision tests on Architect i2000SR and Cobas E601 platforms. Nevertheless, the CEA analysis for each patient should be performed with the same reagents on the same analyzer despite their comparability. One of the problems is the long-term 
monitoring because patients can change the hospital or the laboratory can introduce a new method of evaluation of tumor markers. Ideally, the results obtained by different methods should be fully comparable. In the future, it will be necessary to define a new baseline concentration of CEA for monitoring each patient. In addition, it is necessary to perform standardization and harmonization of different CEA immunoassays in the future.

\section{REFERENCES}

1. Abeloff MD, Armitage JO, Lichter AS, Niederhuber JE. Clinical Oncology. $2^{\text {nd }}$ ed. Edinburgh: Churchill Livingstone; 2000.

2. Duffy MJ, van Dalen A, Haglund C, Hansson L, Klapdor R, Lamerz R, et al. Clinical utility of biochemical markers in colorectal cancer: European group on tumour markers (EGTM) guidelines. Eur J Cancer 2003;39:718-27. https://doi.org/10.1016/S0959-8049(02)00811-0.

3. Serdarevic N, Biletic N, Serdarevic R. Serum values of CEA and CA 19-9 in colorectal cancer. Clin Chem Lab Med 2017;55:S443.

4. Asad-Ur-Rahman F, Saif MW. Elevated level of serum carcinoembryonic antigen (CEA) and search for a malignancy: A case report. Cureus 2016;8(6):e648.

https://doi.org/10.7759/cureus.648.

5. Serdarevic N, Mehanovic $S$. The possible role of tumor antigen $C A$ 15-3, CEA and ferritin in malignant and benign disease. J Health Sci 2012;2(2):138-43.

https://doi.org/10.17532/jhsci.2012.52.

6. Serdarevic N, Serdarevic R, Memic A. Comparison of three immunoassays in the determination of tumor marker CA 15-3 levels in human serum. J Health Sci 2016;6(3):154-61.

7. Arneson W, Brickell J. Clinical Chemistry a Laboratory perspective. $1^{\text {st }}$ ed. Philadelphia, PA: F.A. Davis Company; 2007. p. 131-46.

8. Vesper HW, Thienpont LM. Traceability in laboratory medicine. Clin Chem 2009;55:1067-75.

https://doi.org/10.1373/clinchem.2008.107052.

9. International Organization for Standardization. In vitro Diagnostic Medical Devices-Measurement of Quantities in Biological SamplesMetrological Traceability of Values Assigned to Calibrators and Control Materials. ISO 17511. Geneva, Switzerland: International Organization for Standardization; 2003.
10. Zhang $\mathrm{K}$, Huo H, Lin G, Yue Y, Wang Q, Li J, et al. A long way to go for the harmonization of four immunoassays for carcinoembryonic antigen. Clin Chim Acta 2016;454:15-9.

https://doi.org/10.1016/j.cca.2015.12.029.

11. Bishop ML, Fody EP, Schoeff LE. Clinical Chemistry: Techniques, Principles, Correlation. $6^{\text {th }}$ ed. Philadelphia, PA: Wolters Kluwer Health/ Lippincott Williams and Wilkins; 2010. p. 637-51.

12. Sturgeon CM, Duffy MJ, Stenman UH, Lilja H, Brünner N, Chan DW, et al. National academy of clinical biochemistry laboratory medicine practice guidelines for use of tumor markers in testicular, prostate, colorectal, breast, and ovarian cancers. Clin Chem 2008;54:e11-79.

https://doi.org/10.1373/clinchem.2007.094144;

https://doi.org/10.1373/clin chem.2008.105601.

13. Zhang GM, Guo XX, Ma XB, Zhang GM. Reference intervals of alpha-fetoprotein and carcinoembryonic antigen in the apparently healthy population. Med Sci Monit 2016;22:4875-80.

https://doi.org/10.12659/MSM.901861.

14. Hendriks HA, Kortlandt W, Verweij WM. Standardized comparison of processing capacity and efficiency of five new-generation immunoassay analyzers. Clin Chem 2000;46(1):105-11.

15. Park J, Lee S, Kim Y, Choi A, Lee H, Lim J, et al. Comparison of four automated carcinoembryonic antigen immunoassays: ADVIA centaur XP, ARCHITECT I2000sr, elecsys E170, and unicel dxi800. Ann Lab Med 2018;38(4):355-61. https://doi.org/10.3343/alm.2018.38.4.355.

16. Sturgeon CM, Seth J. Why do immunoassays for tumour markers give differing results?-a view from the UK national external quality assessment schemes. Eur J Clin Chem Clin Biochem 1996;34(9):755-9.

17. Sturgeon $\mathrm{C}$. Practice guidelines for tumor marker use in the clinic. Clin Chem 2002;48(8):1151-9.

18. Serdarevic N, Stanciu AE. Comparison of architect i2000 for determination of SCC with IMX determination of SCC with different methods. Clin Lab 2013;59:1129-33.

https://doi.org/10.7754/Clin.Lab.2013.121133.

19. Serdarevic N. Comparison of architect chemiluminescent microparticle immunoassay for determination of Troponin I in serum with AXSYM MEIA technology. J Health Sci 2011;1(3):154-8.

https://doi.org/10.17532/jhsci.2011.130.

20. Serdarevic $N$. The comparison between different immunoassays for serum carbohydrate antigen (CA 19-9) concentration measurement. Acta Inform Med 2018;26(4):235-9.

https://doi.org/10.5455/aim.2018.26.235-239. 